NASA/TM—2007-214814

\title{
Lunar Dust on Heat Rejection System Surfaces: Problems and Prospects
}

James R. Gaier and Donald A. Jaworske

Glenn Research Center, Cleveland, Ohio 


\section{NASA STI Program . . . in Profile}

Since its founding, NASA has been dedicated to the advancement of aeronautics and space science. The NASA Scientific and Technical Information (STI) program plays a key part in helping NASA maintain this important role.

The NASA STI Program operates under the auspices of the Agency Chief Information Officer. It collects, organizes, provides for archiving, and disseminates NASA's STI. The NASA STI program provides access to the NASA Aeronautics and Space Database and its public interface, the NASA Technical Reports Server, thus providing one of the largest collections of aeronautical and space science STI in the world. Results are published in both non-NASA channels and by NASA in the NASA STI Report Series, which includes the following report types:

- TECHNICAL PUBLICATION. Reports of completed research or a major significant phase of research that present the results of NASA programs and include extensive data or theoretical analysis. Includes compilations of significant scientific and technical data and information deemed to be of continuing reference value. NASA counterpart of peer-reviewed formal professional papers but has less stringent limitations on manuscript length and extent of graphic presentations.

- TECHNICAL MEMORANDUM. Scientific and technical findings that are preliminary or of specialized interest, e.g., quick release reports, working papers, and bibliographies that contain minimal annotation. Does not contain extensive analysis.

- CONTRACTOR REPORT. Scientific and technical findings by NASA-sponsored contractors and grantees.
- CONFERENCE PUBLICATION. Collected papers from scientific and technical conferences, symposia, seminars, or other meetings sponsored or cosponsored by NASA.

- SPECIAL PUBLICATION. Scientific, technical, or historical information from NASA programs, projects, and missions, often concerned with subjects having substantial public interest.

- TECHNICAL TRANSLATION. Englishlanguage translations of foreign scientific and technical material pertinent to NASA's mission.

Specialized services also include creating custom thesauri, building customized databases, organizing and publishing research results.

For more information about the NASA STI program, see the following:

- Access the NASA STI program home page at http://www.sti.nasa.gov

- E-mail your question via the Internet to help@sti.nasa.gov

- Fax your question to the NASA STI Help Desk at 301-621-0134

- Telephone the NASA STI Help Desk at 301-621-0390

- Write to: NASA Center for AeroSpace Information (CASI) 7115 Standard Drive Hanover, MD 21076-1320 
NASA/TM-2007-214814

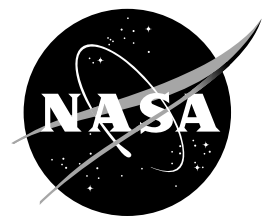

\section{Lunar Dust on Heat Rejection System Surfaces: Problems and Prospects}

James R. Gaier and Donald A. Jaworske

Glenn Research Center, Cleveland, Ohio

Prepared for the

Space Technology and Applications International Forum (STAIF-2007)

sponsored by the Institute for Space and Nuclear Power Studies at the University of New Mexico Albuquerque, New Mexico, February 11-15, 2007

National Aeronautics and

Space Administration

Glenn Research Center

Cleveland, Ohio 44135 


\section{Acknowledgments}

The authors thank Ronald A. Creel, Ryan Associates, Inc., Crystal City, VA, for many helpful discussions and thermal data on the LRV batteries

Level of Review: This material has been technically reviewed by technical management.

Available from

NASA Center for Aerospace Information

7115 Standard Drive

Hanover, MD 21076-1320
National Technical Information Service 5285 Port Royal Road Springfield, VA 22161

Available electronically at http://gltrs.grc.nasa.gov 


\title{
Lunar Dust on Heat Rejection System Surfaces: Problems and Prospects
}

\author{
James R. Gaier and Donald A. Jaworske \\ National Aeronautics and Space Administration \\ Glenn Research Center \\ Cleveland, Ohio 44135
}

\begin{abstract}
Heat rejection from power systems will be necessary for human and robotic activity on the lunar surface. Functional operation of such heat rejection systems is at risk of degradation as a consequence of dust accumulation. The Apollo astronauts encountered marked degradation of performance in heat rejection systems for the lunar roving vehicle, science packages, and other components. Although ground testing of dust mitigation concepts in support of the Apollo mission identified candidate mitigation tools, the brush concept adopted by the Apollo astronauts proved essentially ineffective. A better understanding of the issues associated with the impact of lunar dust on the functional performance of heat rejection systems and its removal is needed as planning gets underway for human and robotic missions to the Moon. Renewed emphasis must also be placed on ground testing of pristine and dust-covered heat rejection system surfaces to quantify degradation and address mitigation concepts. This paper presents a review of the degradation of heat rejection systems encountered on the lunar surface to-date, and discusses current activities underway to evaluate the durability of candidate heat rejection system surfaces and current dust mitigation concepts.
\end{abstract}

\section{Introduction}

Lunar dust will only degrade heat rejection system surfaces if it is transported onto them. Transport mechanisms can be divided into two categories, natural and anthropogenic. The two known natural mechanisms are meteoroid impacts and electrostatic transport. As meteoroids impinge upon the surface of the Moon, they elevate an amount of dust equaling about one hundred times their mass (Zook, 1984).

Christiansen (2003) has analyzed the frequency of meteoroid strikes as a function of size for spacecraft in low Earth orbit, with the results being reproduced in figure 1. Since the Moon occupies a similar position in the solar system, but with a weaker gravity well, these values are considered conservative for meteoroid impacts on the lunar surface. For example, the probability that a 1-cm-diameter meteoroid will impinge upon a square area $100 \mathrm{~m}$ on a side is about once in $50 \mathrm{yr}$. Such an impact would elevate about $250 \mathrm{~g}$ of dust. Similarly, one hundred $1 \mathrm{~mm}$ diameter meteoroids would impinge on the same area per year, with each raising about $25 \mathrm{mg}$ of dust. Katzan and Edwards (1991) have estimated that the total dust accumulation from primary and secondary micrometeoroid impacts to be about $0.1 \mathrm{~g} / \mathrm{m}^{2}$-yr.

The movement of lunar fines due to electrostatic transport at or near the lunar terminator, while once controversial, is gaining wide acceptance among the lunar science community. There is photographic evidence taken by spacecraft in orbit and evidence from the Apollo 17 Cosmic Dust Experiment (Berg, et al., 1974). The amount of dust elevated through this process has been estimated by Rennilson and Criswell (1974) to be as much as $300 \mathrm{~g} / \mathrm{m}^{2}$-yr. However, calculations based on laser ranging measurements from corner-cube reflectors left on the lunar surface during Apollo 11, 14, and 15 suggest that there should be no appreciable degradation in the corner-cube mirrors for hundreds of years (Silverberg, 1975). These calculations are inferring that the amount of dust deposited onto the cornercube reflectors over the years is far below the estimate of Rennilson and Criswell. Thus, natural sources of dust transport would not be expected to pose a significant threat to heat rejection system surfaces. 


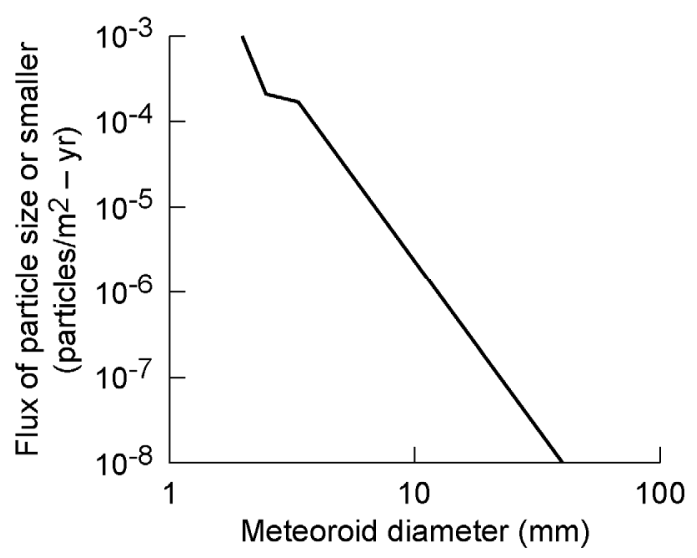

Figure 1.-Frequency of meteoroid strikes as a function of size (after Christiansen, 2003).

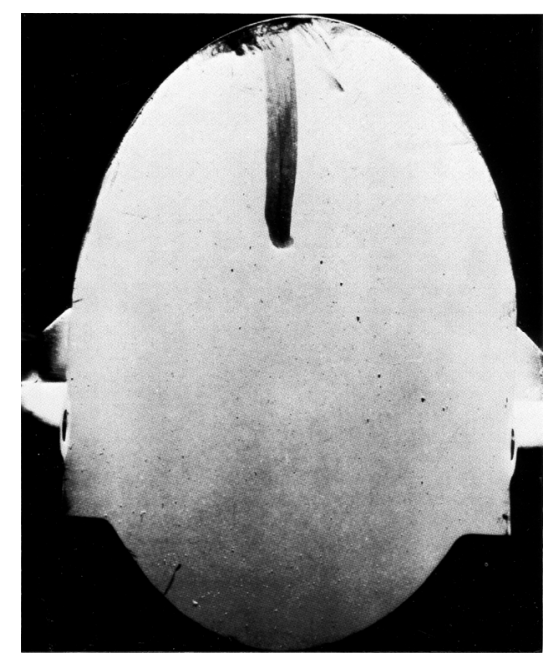

Figure 2.-Photograph of the Surveyor 3 camera mirror covered in lunar dust (Nickel, 1972).

Although natural dust transport mechanisms are not expected to significantly degrade the performance of heat rejection system surfaces, the same cannot be said of anthropogenic mechanisms. These mechanisms include the engine plume from landing and launching, construction activities (such as digging and drilling), lunar roving vehicle operations, and walking. With no appreciable atmosphere, dust particles once set in motion will, to first order, follow Newton's laws of projectile motion. An analysis of the impact of these activities by Katzan and Edwards (1991) found that, by a large margin, dust is expected to be most widely transported by landing and launching. Movement of lunar dust due to engine plume was observed by Apollo astronauts at altitudes of about $35 \mathrm{~m}$ (Gaier, 2005). Apollo observations, ground testing, and analysis reveal that, due to the pressure wave from the exhaust plume, dust particle trajectories are very nearly horizontal to the surface (Reiss and Shaffer, 1991). The Apollo 12 lunar module landed $155 \mathrm{~m}$ from Surveyor 3, and the resulting impact of that landing on Surveyor 3 has been studied through components returned to Earth. Lunar dust particles accelerated upon landing sandblasted the entire exposed surface, and substantial amounts of dust were deposited on the spacecraft. For example, the camera mirror shown in figure 2 was covered with a continuous layer of dust (Nickel and Carroll, 1972). Of additional interest, samples retrieved from Surveyor 3 after 31 months exposure to the lunar surface revealed that the cabling had become brittle and the white thermal control paint was tan (Wilson, 1987). With just one nearby landing, Surveyor 3 accumulated a layer of dust $1 \mathrm{mg} / \mathrm{cm}^{2}$ (Caroll and Blair, 1972). It has been estimated that multiple landings and departures at a lunar outpost may affect areas as far away as $1.5 \mathrm{~km}$ (Katzan and Edwards, 1991). 
Other activities that have been suggested as sources of anthropogenic dust transport include, in order of decreasing concern, lunar construction, mining, and other in-situ resource utilization operations, lunar roving vehicle operations, suit cleaning, and extravehicular activity (EVA) including walking and carrying out scientific investigations. Photographs of lunar roving vehicle operations have shown that dust is thrown from the wheels in a "rooster tail" with particles traveling as far as $20 \mathrm{~m}$ from their source. Particles kicked up by walking can reach heights of several meters and can land as far as $8 \mathrm{~m}$ form their source. (Katzan and Edwards, 1991).

The objective of this paper is to review the degradation of heat rejection systems on the lunar surface and to discuss the prospects for improving the thermal performance of future heat rejection systems. The paper also discusses activities now underway to evaluate the durability of heat rejection system surfaces and dust mitigation concepts.

\section{Lunar Dust Effects on Heat Rejection System Surfaces}

Perhaps the most instructive lessons learned from Apollo on the effects of lunar dust on heat rejection system surfaces come from the radiators that cooled the batteries on the Lunar Roving Vehicle (LRV). The radiators were second surface mirrors with front surfaces composed of fused silica. The lunar dust has a high emittance (about 0.93 ), so there was little concern about the ability of the radiators to reject heat through a dust layer (Tatom, et al., 1967). However, the dust also has a relatively high absorptance (about 0.76 ), so there was concern that there would be an additional heat load from solar heating if there was a significant amount of dust on the radiators (Blair, et al., 1971). These batteries had an operating range of 4 to $51{ }^{\circ} \mathrm{C}$, and operated in an ambient environment that ranged from $10^{\circ} \mathrm{C}$ at the beginning of the mission to $82{ }^{\circ} \mathrm{C}$ at its end.

The batteries were located on the front of the LRV, and so were expected to have a fair amount of dust impinging on them. Thus, the design for the battery radiators included dust covers. The plan was for the dust covers to be opened, exposing the second surface mirror radiators to cool the batteries between periods of EVA. It was anticipated that despite the precaution of the dust covers, that some dust would still find its way onto the radiators. However, a study by Jacobs, Durkee, and Harris (1971), which utilized lunar regolith returned by Apollo 12 concluded that removing lunar dust from fused silica second surface mirrors with a nylon brush would be effective. This was the strategy utilized to remove the dust from the radiators on all three LRVs for Apollo 15, 16, and 17. However, the experience on the lunar surface was very different from that which was modeled and simulated beforehand. In Apollo 15 there was good battery cool down between EVA-1 and EVA-2, but after dust found its way onto the radiators, there was essentially no cool down between EVA-2 and EVA-3 (McKay, 1971). Both batteries warmed to about $47^{\circ} \mathrm{C}$, about $4{ }^{\circ} \mathrm{C}$ below their maximum rated operating temperature. On Apollo 16 the batteries only cooled down $11^{\circ} \mathrm{C}$ instead of the $28^{\circ} \mathrm{C}$ expected, and reached their operating limit at the end of the second EVA. After the cool down period, at the beginning of the third EVA the batteries had only cooled about $2{ }^{\circ} \mathrm{C}$. At the end of the third EVA the temperature had exceeded the maximum rated survival temperature, as shown in figure 3 (McKay, 1972). The battery temperature profile on Apollo 17 was similar to that of Apollo 16 and after a little more than $4 \mathrm{hr}$ into the third EVA the batteries exceeded their maximum operating temperature. By $6 \mathrm{hr}$, the batteries had reached their maximum survival temperature (McKay, 1973). Apparently, lunar dust under lunar surface conditions is much more adherent than under the terrestrial simulation conditions chosen by Jacobs, Durkee, and Harris (1971). This was especially true for the finest fraction of the dust, which was not removed at all by brushing. Since solar heat load is proportional to the fractional coverage, this fine fraction soon covered most of the surface and dominated heat transfer. The lesson here is that the simulation of the lunar environment must be of high fidelity, more than just a simple vacuum chamber, if useful results are to be obtained.

The Apollo Lunar Surface Experiment Package (ALSEP), a collection of experiments deployed by Apollo 12, also experienced higher than predicted temperatures while on the lunar surface (Harris, 1972). Pre-flight qualifications included thermal vacuum tests, but no tests were done to evaluate the effects of 


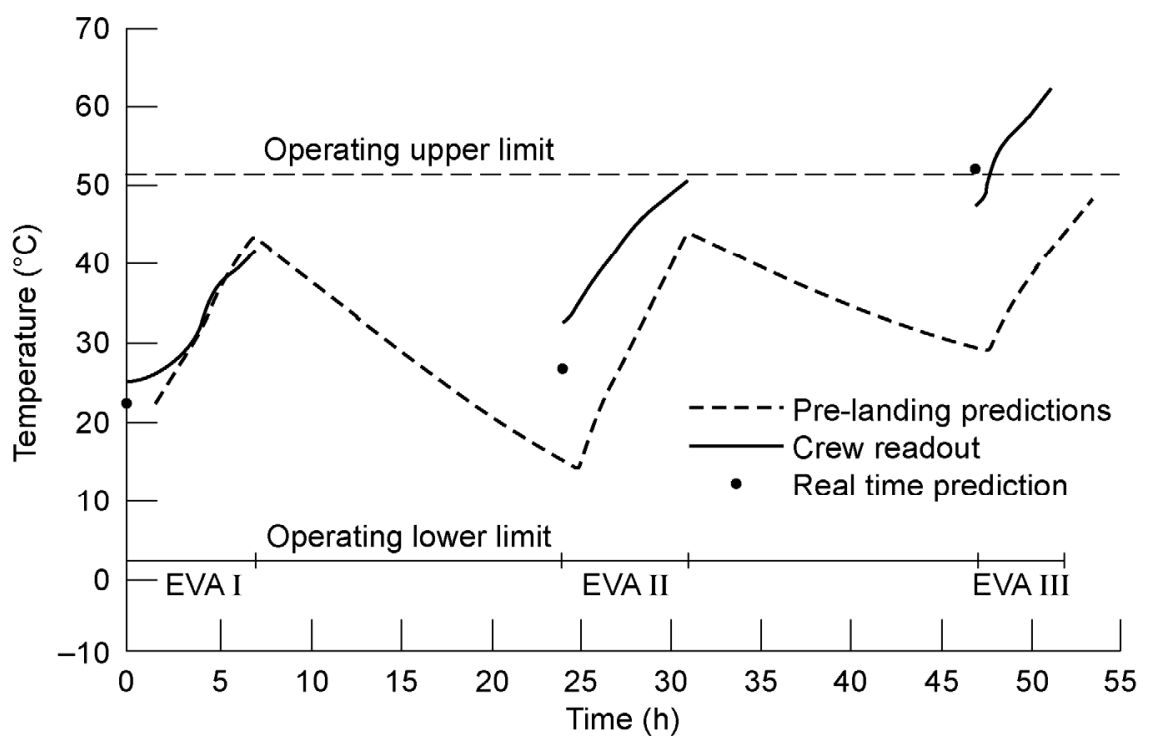

Figure 3.-Actual and predicted temperature excursions in lunar roving vehicle batteries (McKay, 1972).

lunar dust. The Lunar Surface Magnetometer was designed for a maximum temperature of $65^{\circ} \mathrm{C}$. This was exceeded when the sun angle was between $55^{\circ}$ and $140^{\circ}$ (a duration of about 6.6 days) because of dust on thermal control surfaces, reaching a temperature of about $79^{\circ} \mathrm{C}$. Similarly, the Passive Seismic Experiment Package was predicted to have a maximum temperature of $61{ }^{\circ} \mathrm{C}$ but had an actual maximum temperature of $89^{\circ} \mathrm{C}$ after contamination by dust, debris, or combustion products from the ascent of the Lunar Module. The ALSEP serves as a warning for contamination of thermal control surfaces on science packages, which tend to be small and have radiators close to the ground, and for thermal control surfaces on equipment placed near launching areas.

Previous ground testing of various radiator materials at elevated temperatures utilizing lunar simulant has indicated that iron from the basaltic simulant diffused into some materials and not into others (Jaworske and Jain, 1993). Niobium and niobium-1\% zirconium exhibited an increase in mass upon exposure to the basalt while molybdenum and carbon showed no increase in mass. Such observations suggest the need for testing of surfaces and coatings at their anticipated operating temperatures.

\section{Prospects for Improving Thermal Performance}

The Apollo experience points out the difficulties that can be encountered in maintaining effective thermal control in a long-term lunar outpost. The LRV radiator performance was seriously degraded after a single exposure to lunar dust and contemporary cleaning techniques were ineffective. The science mission objectives of ALSEP were put at risk owing to overheating as a result of lunar dust exposure. Entirely new strategies for dealing with dust must be developed for effective, long-term thermal control.

Three strategies can be developed for this long-term thermal control. First, systems can be designed that tolerate an accumulation of lunar dust. These might take advantage of the high emittance of the dust. Perhaps systems will be developed that will even require the application of a layer of lunar dust prior to use. The second strategy is to design thermal control surfaces that will minimize the accumulation of lunar dust. These might include surfaces that are passive such that the nature of the surface either repels dust or has such low adhesive forces that the dust falls off on its own or upon inverting, or surfaces that are active such as a field that repels the dust away from the surface. The third strategy is to develop effective methods of cleaning dust from the thermal control surface. The most successful technologies might indeed incorporate two or three of these strategies.

There have been very few proposals to utilize the first strategy, to make heat rejection surfaces that tolerate dust accumulation. The difficulty lies with the high solar absorptance mentioned above and the 
low thermal conductivity of the dust, thought to be on the order of $5 \times 10^{-4} \mathrm{~W} / \mathrm{m}-\mathrm{K}$. Calculations indicate that a coating of dust $1 \mathrm{~mm}$ thick would raise the steady state temperature of a radiator having an emittance of 0.85 and designed to reject $100 \mathrm{~W} / \mathrm{m}^{2}$ by $75^{\circ} \mathrm{C}$. This is a difficult technological problem.

There have been several strategies proposed to minimize the accumulation of lunar dust. One passive system that has been proposed is to apply a texture to the heat rejection surface that is much finer than the typical grain size. This is the same strategy that nature utilizes on the leaves of lotus plants to repel water (Cheng, et al., 2006), and on the feet of geckos to keep terrestrial dust particles from clogging the small structures on their feet that enable them to climb smooth walls. In essence, the dust particles reside on a nanoscale "bed of nails" instead of a smooth surface. This results in a much lower contact area yielding much lower adhesive forces.

A second type of passive system acts not on the thermal control coating, but on the environment surrounding the heat rejection system surface. Taylor et al. (2005) have noted that the nanophase iron present in lunar dust renders it an effective microwave absorber. He has proposed that the particles in the regolith located near sensitive surfaces, like radiators, be sintered together utilizing only modest power. Even if this did not trap all of the dust particles, it certainly might reduce their abundance to the point that they have negligible effect on the thermal radiative properties of nearby heat rejection system surfaces.

One active system that has been proposed to minimize the accumulation of dust is an electrostatic fence. In this concept, an $\alpha$-particle source, such as ${ }^{210} \mathrm{Po}$ is placed near the edge of a thermal control surface. The $\alpha$-particles, which have a long range in vacuum, accumulate on the dust particles giving them a positive charge. A negatively charged plate is located nearby which attracts the now positively charged dust particles, keeping them from reaching the thermal control surface. When the particle hits the negatively charged plate, the charge is neutralized and the dust particle slides off the plate back onto the surface. The same concept with opposite polarity could use a $\beta$-particle emitter and a positively charged plate. This system has the advantage that many dust particles will already be negatively charged by photodissociation due to solar ultraviolet light.

There have also been many proposals of ways to clean dust from thermal control surfaces. One simple solution is to have a series of infrared transparent layers on top of the thermal control surface. When the dust accumulation becomes too large, the top layer is simply pealed away, exposing a fresh surface. Taylor (2000) has also suggested that the nanophase iron in the lunar dust makes it susceptible to being removed by a magnet. This method is most effective in removing the smallest particles. Perhaps the larger particles can be removed by mechanical brushing and the smaller with magnetic brushing. This could be automated so that periodically a brush sweeps over the thermal control surface followed by a magnetic wand.

Others have suggested that the dust be blown off utilizing a puff of gas. Or perhaps, instead of gas phase cleaning agents, condensed phases are more effective. Early studies using carbon dioxide or water, which freezes to a snow that knocks particles off of surfaces, may be more effective than simple gases (Tatom et al., 1967).

Immer et al. (2006), have shown that a radio-frequency field with phase shifting can remove small particles under terrestrial and Martian conditions. Although this technique has not been as effective under vacuum conditions, to-date, little effort has gone into optimizing the parameters to lunar environmental conditions (Calle, 2006).

Additional concepts will undoubtedly be proposed in the future and their strengths and weakness will need to be evaluated on a case-by-case basis.

\section{Testing Thermal Performance}

One of the lessons of the Apollo LRV radiator experience is that qualification testing requires a high fidelity lunar environment. Jacobs, Durkee, and Harris (1971) had actual lunar dust and a good vacuum chamber, and their results were still misleading. What were the sources of error in the simulation? Was the surface of the dust too contaminated with terrestrial species? Was the problem in improper illumination? Was the presence of solar wind required? Was the thermal environment wrong? Was the 
vacuum simply not good enough? Was there a charging effect that was unaccounted for? Does the higher gravitation of Earth have an effect? At this point, there are no clear cut answers to these questions. What is known is that the fine dust particles were removed in the simulation, but not in the lunar environment.

The Lunar Dust Adhesion Bell jar (LDAB) at the NASA Glenn Research Center was developed to provide a high fidelity lunar dust simulation environment in which to determine the important variables for dust adhesion on sensitive surfaces, including those utilized by heat rejection systems. The LDAB has the ability to bake out lunar dust simulants, or actual lunar regolith, under vacuum. It can thermal cycle the simulant and subject it to a hydrogen/helium plasma environment. Residual gas composition can be monitored with a mass spectrometer. Once activated, the dust can be sieved onto a sample and the coverage determined by a microscopic camera or a quartz crystal microbalance. The temperature of coupons coated with thermal control coatings of interest can be monitored while being heated by a xenon arc lamp and cooled under a cold wall. The effect of the dust coverage on the absorptance and emittance can be determined from dynamic thermal behavior, or a known amount of power can be fed to the sample under the cold wall and the steady state temperature can be determined. The salient features of the LDAB are summarized in the artist's rendition shown in figure 4. Utilizing these features, in combination, the LDAB offers the highest fidelity simulation of the lunar dust environment on Earth.

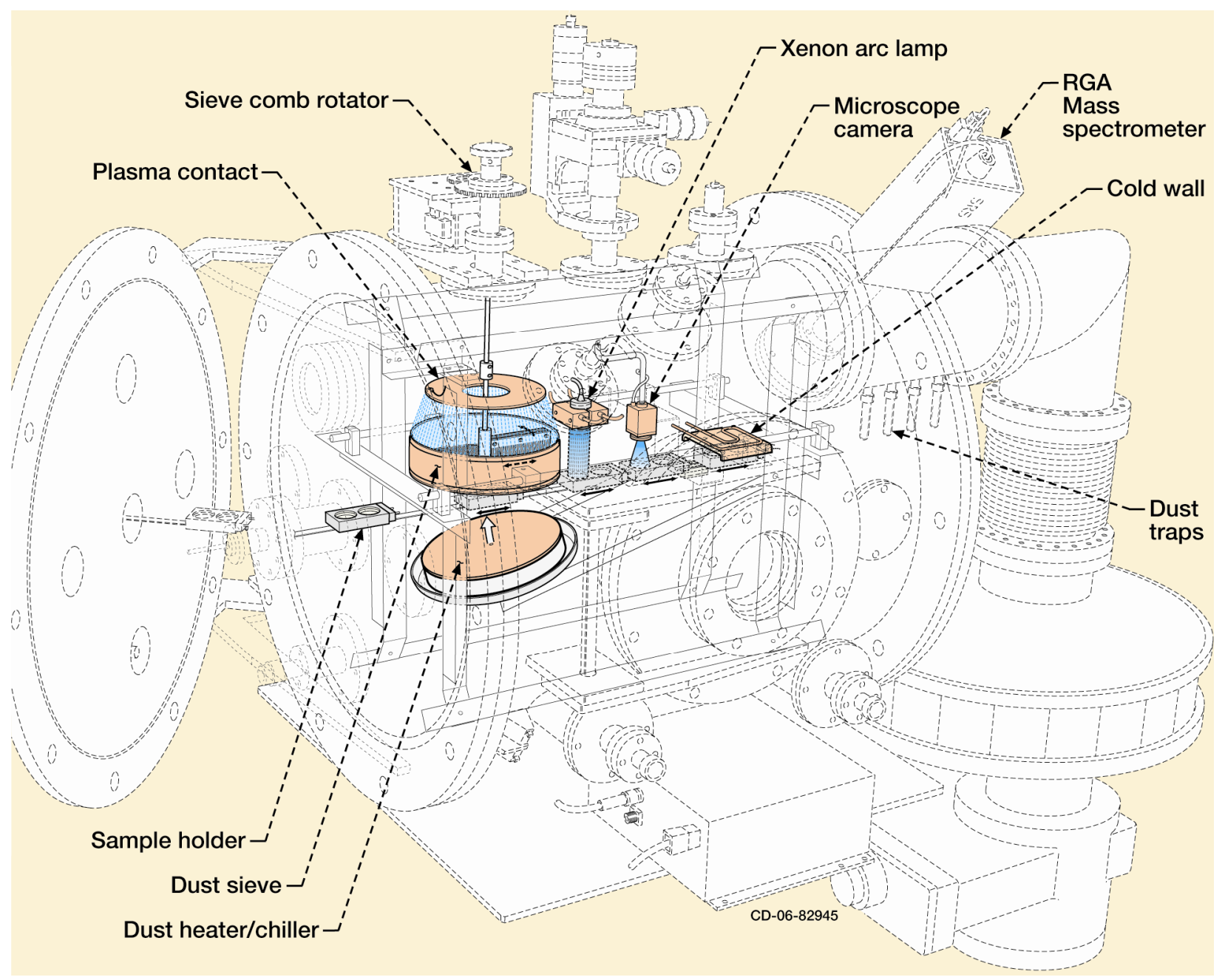

Figure 4.-Artist's rendition of the Lunar Dust Adhesion Bell (LDAB) jar. 
Experiments will be designed to determine which environmental characteristics have the most effect on the adhesion of dust to thermal control surfaces, as well as other surfaces of interest such as solar cells, helmet visors, and EVA suit materials. Additional experiments will explore technologies for dust tolerance, technologies to limit adhesion of dust to surfaces, and technologies to clean dust from surfaces. Armed with this information, heat rejection system surfaces can be designed that will meet the challenges of establishing a permanent human presence on the Moon.

\section{Conclusion}

Problems identified during the Apollo experience illustrate the impact of lunar dust on heat rejection surfaces. Dust laden exhaust plumes from the landing of the Apollo 12 lunar module sandblasted a nearby spacecraft. Batteries on lunar roving vehicles reached or exceeded their maximum operating temperature due to dust covered radiators, despite ground tests suggesting that contemporary solutions would remove dust effectively. Science mission objectives for the Apollo Lunar Surface Experiment Package were put at risk due to overheating. Chemical interactions may pose a threat to surfaces operating at high temperatures. Lunar dust presents a huge problem for future long duration outpost missions. However, the prospects for developing heat rejection system surfaces that are durable to the lunar dust environment are promising. Currently under study are concepts incorporating one or more of the following strategies: designing dust tolerant surfaces that can operate in the presence of dust, utilizing passive coatings to remove dust from surfaces to prevent significant accumulation, sintering nearby regolith to minimize dust transport, or developing active dust removal technologies to remove dust once its presence begins to effect thermal performance. As part of this renewed effort, the Lunar Dust Adhesion Bell jar was developed to provide high fidelity simulation of the lunar dust environment. It is currently being used to study the impact of dust coverage on surfaces and will be used to study the impact of various dust abatement technologies that will be important for developing the heat rejection system surfaces needed for establishing a permanent human presence on the Moon.

\section{References}

Berg, O.E., Richardson, F.F., Rhee, J.W., and Auer, S., Preliminary Results of a Cosmic Dust Experiment on the Moon, Geophysical Research Letters, 1 (7), 289-290, (1974).

Blair, Jr., P.M., Carroll, W.F., Jacobs, S., and Leger, L.J., "Study from Thermal Control Surfaces Returned from Surveyor III," in the proceedings of AIAA 6th Thermophysics Conference, AIAA, Reston, VA, AIAA Paper 71-479.

Calle, C., Private Communications, 2006.

Caroll, W.F. and Blair, Jr., P.M., Lunar Dust and Radiation Darkening of Surveyor 3 Surfaces, Analysis of Surveyor 3 Materials and Photographs Returned by Apollo 12, NASA SP-284, NASA

Headquarters, Washington D.C., 1972.

Cheng, Y.T., et al., "Effects of Micro and Nano-Structures on the Self-Cleaning Behavior of Lotus Leaves," Nanotechnology 17, 1359-1362, (2006).

Christiansen, E., Meteoroid/Debris Shielding, NASA/TP—2003-210788, NASA Johnson Space Center, Houston, TX, 2003.

Gaier, J.R., The Effects of Lunar Dust on EVA Systems During the Apollo Missions, NASA/TM-2005213610, NASA Glenn Research Center, Cleveland, OH, 2005.

Harris, Jr., R.S., Apollo Experience Report: Thermal Design of Apollo Lunar Surface Experiment Package, NASA TN D-6738, Manned Spacecraft Center, Houston, TX,1972.

Immer, C., et al., "Electrostatic Screen for Transport of Martian and Lunar Regolith," in the proceedings of 37th Lunar and Planetary Science Conference, Lunar and Planetary Institute, Houston, TX, 2006, pp. 2265. 
Jacobs, S., Durkee, R.E., and Harris, Jr., R.S., "Lunar Dust Deposition Effects on the Solar Absorptance of Thermal Control Materials," in the proceedings of AIAA 6th Thermophysics Conference, AIAA, Reston, VA, AIAA Paper 71-459.

Jaworske, D.A. and Jain, S.K., "Chemical Interactions Between Candidate Radiator Materials and Simulated Lunar Basalt at Temperatures up to $1273 \mathrm{~K}$," in the proceedings of 10h Sym. on Space Nuclear Power and Propulsion, edited by M.S. El-Genk and M.D. Hoover, 1993, pp. 683-688.

Katzan, C. and Edwards, J., Lunar Dust Transport and Potential Interactions with Power System Components, NASA CR-4404, NASA Lewis Research Ctr., Cleveland, OH, 1991.

McKay, G.H., Saturn V Launch Vehicle Flight Evaluation Report-AS-510, Apollo 15 Mission, Saturn V Flight Evaluation Working Group, NASA Marshall Space Flight Ctr., Huntsville, AL, 1971.

McKay, G.H., Saturn V Launch Vehicle Flight Evaluation Report-AS-511, Apollo 16 Mission, Saturn V Flight Evaluation Working Group, NASA Marshall Space Flight Ctr., Huntsville, AL 1972.

McKay, G.H., Saturn V Launch Vehicle Flight Evaluation Report-AS-512, Apollo 17 Mission, Saturn V Flight Evaluation Working Group, NASA Marshall Space Flight Ctr., Huntsville, AL 1973.

Nickel, N.L. and Carroll, W.F., Summary and Conclusions. Analysis of Surveyor III Material and Photographs Returned by Apollo 12, NASA SP-284, NASA Headquarters, Washington D.C., 1972.

Reiss, J.R., and Shaffer, J.R., Lunar Transportation Facilities and Operations Study-Option 1, Final Report for NASA Contract NAS10-11567, NASA Kennedy Space Ctr., FL, 1991.

Rennilson, J.J. and Criswell, D.R., "Surveyor Observations of Lunar Horizon Glow," The Moon, 10, 121142, (1974).

Silverberg, E.C., Electrostatic Dust Transport and its Consequences for the Lunar Ranging Experiment, University of Texas McDonald Observatory Research Memorandum in Astronomy \#75-003, Fort Davis, TX, 1975.

Tatom, F.B., et al., Lunar Dust Degradation Effects and Removal/Prevention Concepts Final Report, NASA TR-792-7-207, NASA Marshall Space Flight Center, Huntsville, AL, 1967.

Taylor, L.A., "The Lunar Dust Problem: A Possible Remedy," in the proceedings of Space Resources Roundtable II, Golden, CO, 2000, pp. 7004.

Taylor, L.A., et al., "The Lunar Dust Problem: From Liability to Asset," in the proceedings of AIAA 1st Space Exploration Conference, Reston, VA, AIAA Paper 2005-2510.

Wilson, A., Solar System Log, Jane's, New York, NY, 1987, pp. 45-47.

Zook, H.A., "Lunar Primary and Secondary Microcraters and the Micrometeoroid Flux," in the proceedings of 15th Lunar and Planetary Science Conference, Lunar and Planetary Institute, Houston, TX, 1984, pp. 965-966. 


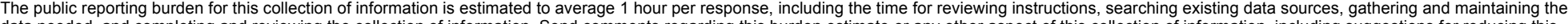

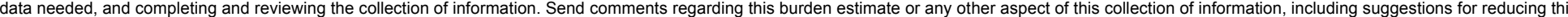

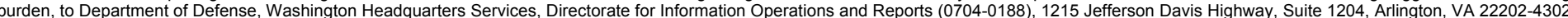

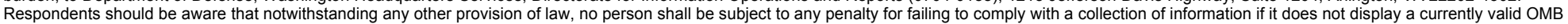
control number.

PLEASE DO NOT RETURN YOUR FORM TO THE ABOVE ADDRESS.

\section{REPORT DATE $(D D-M M-Y Y Y Y)$ \\ 2. REPORT TYPE \\ 3. DATES COVERED (From - To)}

14-06-2007

Technical Memorandum

\section{TITLE AND SUBTITLE}

Lunar Dust on Heat Rejection System Surfaces: Problems and Prospects

\section{5a. CONTRACT NUMBER}

5b. GRANT NUMBER

5c. PROGRAM ELEMENT NUMBER

5d. PROJECT NUMBER

Gaier, James, R.; Jaworske, Donald, A. 5e. TASK NUMBER

5f. WORK UNIT NUMBER

WBS 997180.10.03.0

\section{PERFORMING ORGANIZATION}

REPORT NUMBER

E-15970

National Aeronautics and Space Administration

John H. Glenn Research Center at Lewis Field

Cleveland, Ohio 44135-3191

\section{SPONSORING/MONITORING AGENCY NAME(S) AND ADDRESS(ES)}

National Aeronautics and Space Administration

Washington, DC 20546-0001

\begin{tabular}{l} 
10. SPONSORING/MONITORS \\
ACRONYM(S) \\
NASA \\
\hline $\begin{array}{l}\text { 11. SPONSORING/MONITORING } \\
\text { REPORT NUMBER } \\
\text { NASA/TM-2007-214814; STAIF Paper } \\
\text { number 26 }\end{array}$
\end{tabular}

\section{DISTRIBUTION/AVAILABILITY STATEMENT}

Unclassified-Unlimited

Subject Category: 23

Available electronically at http://gltrs.grc.nasa.gov

This publication is available from the NASA Center for AeroSpace Information, 301-621-0390

\section{SUPPLEMENTARY NOTES}

\section{ABSTRACT}

Heat rejection from power systems will be necessary for human and robotic activity on the lunar surface. Functional operation of such heat rejection systems is at risk of degradation as a consequence of dust accumulation. The Apollo astronauts encountered marked degradation of performance in heat rejection systems for the lunar roving vehicle, science packages, and other components. Although ground testing of dust mitigation concepts in support of the Apollo mission identified mitigation tools, the brush concept adopted by the Apollo astronauts proved essentially ineffective. A better understanding of the issues associated with the impact of lunar dust on the functional performance of heat rejection systems and its removal is needed as planning gets underway for human and robotic missions to the Moon. Renewed emphasis must also be placed on ground testing of pristine and dust-covered heat rejection system surfaces to quantify degradation and address mitigation concepts. This paper presents a review of the degradation in performance of heat rejection systems encountered on the lunar surface to-date, and will discuss current activities underway to evaluate the durability of candidate heat rejection system surfaces and current dust mitigation concepts.

\section{SUBJECT TERMS}

Thermal control coatings; Lunar dust; Heat rejection systems; Thermal control surfaces; Optical properties

\begin{tabular}{|c|c|c|c|c|}
\hline 16. SECURI & ASSIFICATION & & 17. LIMITATION OF & 18. NUMBER \\
\hline $\begin{array}{l}\text { a. REPORT } \\
\text { U }\end{array}$ & $\begin{array}{l}\text { b. ABSTRACT } \\
U\end{array}$ & $\begin{array}{l}\text { c. THIS } \\
\text { PAGE } \\
\text { U }\end{array}$ & & $\begin{array}{c}\text { PAGES } \\
14\end{array}$ \\
\hline
\end{tabular}

19a. NAME OF RESPONSIBLE PERSON
Donald A. Jaworske
19b. TELEPHONE NUMBER (include area code)
216-433-2312



